\title{
El Comité de Auditoría
}

\section{CPC Alan Rozas Flores}

Docente Asociado de la Facultad de Ciencias Contables

\section{RESUMEN:}

A partir de los grandes escándalos corporativos que sacudieron al mundo de los negocios, los comités de auditoría han sido objeto de una redefinición de sus funciones y responsabilidades, lo cual ha llegado hasta la inclusión de éstas en leyes, reglamentos y códigos de mejores prácticas a nivel mundial, llevando a las organizaciones a la necesidad de replantear las estructuras y prácticas de sus comités, asi como el reconocer los beneficios que implican el contar con un comité preparado para contribuir al cumplimiento de los objetivos estratégicos de cada organización.

Los miembros del comité de auditoría se enfrentan a altas expectativas de varios grupos, lo que incluye a accionistas, activistas de accionistas y de gobierno corporativo, reguladores, los medios de comunicación y los miembros asociados del directorio. La bolsa de Nueva York, en su listado de propuestas tipo, ha sugerido establecer un proceso formal de evaluación para todo el directorio y para cada comité de mayor importancia del directorio, entre ellos el comité de auditoría.

Un comité de auditoría (o cuerpo equivalente) es establecido por los miembros del directorio (o junta de directores) de la empresa, con el propósito de supervisar los procesos contables y de presentación de información financiera de la empresa y sus estados financieros. Algunas disposiciones y normas nacionales también estipulan que si no existe tal comité, entonces el comité de auditoría es todo el directorio.

La existencia y buen funcionamiento del comité de auditoría son sinónimos de prácticas de buen gobierno corporativo (empresarial). Su efectividad e independencia de actuación genera gran confianza entre socios, inversionistas y acreedores, $e$ incluso de clientes y entidades gubernamentales de supervisión, fiscalización y control. Sin embargo, esto requiere que los miembros de este comité tengan conocimientos, aptitudes, habilidades y experiencia práctica, así como cualidades personales particulares.

Palabras clave: Auditoría externa, auditoría interna, agregar valor, gobierno corporativo, control interno, empresa, Ley Sarbanes-Oxley, Directorio, riesgo. 


\section{INTRODUCCIÓN}

La situación actual exige la implantación de mejores prácticas corporativas y metodologías que permitan a las organizaciones preservar la integridad de sus patrimonios e incrementar el valor de sus acciones en un entorno altamente competitivo. Una de las mejores y buenas prácticas de la empresa es la existencia de un comité de auditoría dentro de su estructura orgánica.

La existencia y buen funcionamiento del comité de auditoría son sinónimos del grado en que las prácticas de gobierno corporativo realmente se aplican. Su efectividad e independencia de actuación generan gran confianza entre socios, inversionistas y acreedores, e incluso de clientes y entidades gubernamentales de supervisión, fiscalización y control.

La independencia del comité de auditoría es una excelente e inmejorable carta de presentación que tiene la empresa ante los mercados de financiamiento, inversionistas, calificadores de valores y de riesgos, clientes y demás usuarios de información financiera y no financiera.

El objetivo general de este artículo es demostrar el rol actual del comité de auditoría, con atributos de moderno, actualizado, responsable y efectivo.

En este contexto, los objetivos específicos están constituidos por ensayar respuestas a interrogantes tales como: qué es el comité de auditoría, cuál es su importancia, cómo está integrado, cuáles son sus funciones y responsabilidades, cómo se da la independencia de sus acciones, cuál es la periodicidad de las reuniones, cómo son las relaciones con los demás directivos, cómo se revisan las recomendaciones y planes de acción, por qué las organizaciones deberían tener un comité de auditoría; y en las empresas donde existe co- mité de auditoría: qué tan eficiente es su funcionamiento, qué tan alineadas se encuentran sus acciones con las prácticas recomendadas, los objetivos, estrategias y necesidades corporativas específicas, qué problemas y, en general, qué debilidades afrontan.

\section{Antecedentes}

A partir de los grandes escándalos corporativos que sacudieron al mundo de los negocios, los comités de auditoría han sido objeto de una redefinición de sus funciones y responsabilidades, lo cual ha llegado hasta la inclusión de estas en leyes, reglamentos y códigos de mejores prácticas a nivel mundial, llevando a las organizaciones a la necesidad de replantear las estructuras y prácticas de sus comités, así como reconocer los beneficios que implican contar con un comité preparado para contribuir en el cumplimiento de los objetivos estratégicos de cada organización.

Es importante reconocer que el responder a las leyes y mejores prácticas ha originado designar presupuestos específicos para fortalecer las funciones de los comités, siendo ahora el reto para las organizaciones aprovechar los beneficios de contar con un comité de auditoría sólido y con prácticas mundialmente recomendadas.

Muchas compañías organizan un comité de auditoría dentro de su directorio para tomar un papel activo en la vigilancia de las políticas y prácticas de presentación de informes financieros y de contabilidad de la compañía. La Bolsa de Valores de Nueva York exige los comités de auditoría y esto ha sido respaldado por la SEC (Securities and Exchange Commission) o Comisión de Títulos, Valores y Cambios de EE.UU., el AICPA (American Institute Of Certified Public Accountants) o Instituto Americano 
de Contadores Públicos Certificados, y la Bolsa «American Stock Exchange».

\section{Definición del Comité de Auditoría}

A continuación se presentan algunas definiciones de reconocidas instituciones, organismos y expertos en la materia:

Es un comité (o cuerpo equivalente) establecido por y dentro de una junta de directores de un emisor, con la finalidad de supervisar los procesos de reportaje de contabilidad y financiero del emisor, y auditorías de los estados financieros del emisor.

(Ley Sarbanes-Oxley Act del 2002, sección 2-3)

Los comités de auditoría por excelencia se consideran órganos de soporte al directorio y cumplen una función de supervisión y vigilancia que contribuyen de manera importante al logro de objetivos de las organizaciones.

(Instituto Mexicano de Contadores Públicos)

El comité de auditoría normalmente es considerado como un comité del directorio formado usualmente por directores que no son ejecutivos de la entidad financiera y que además son independientes de la administración.

(Comité de Basilea)

El comité de auditoría es una unidad staff creada por el consejo de administración, para asegurar el pleno respeto y apoyo a la función de auditoría interna y externa, por parte de todos los integrantes de la organización, para asegurar los objetivos del control interno y para vigilar el cumplimiento de la misión y objetivos de la propia organización. Es una unidad de consulta, asesoría y apoyo de la administración.

(Rodrigo Estupiñán Gaitán, «Los Comités de Auditoría y el Gobierno Corporativo»)
El comité de auditoría es el eslabón independiente de comunicación entre los auditores internos y externos, fiscalizadores independientes del gobierno y la dirección superior. Constituye la garantía de que la administración superior conozca los criterios técnicos y legales utilizados en la organización del ambiente y estructura de control, así como para que se lleven a la práctica las recomendaciones emitidas por la auditoría interna o externa en todos los sectores.

(Rene Fonseca Borja, "Auditoría interna: Un enfoque moderno de planificación, ejecución y control»)

Como se puede inferir de lo anterior, el comité de auditoría tiene el propósito de asistir al directorio en el cumplimiento de sus responsabilidades de vigilancia para el proceso de información financiera, el sistema de control interno sobre los informes financieros, el proceso de auditoría y el proceso de la compañía para vigilar el cumplimiento con las leyes y reglamentaciones, y el código de conducta.

Durante el curso de la auditoría, las coordinaciones y discusiones del comité de auditoría con los auditores externos e internos se centran en debilidades en el control interno, desacuerdos con la gerencia sobre los principios de contabilidad e indicaciones de la presencia de fraude administrativo u otros actos ilegales realizados por los altos empleados de la empresa. Puesto que estas comunicaciones ayudan al comité de auditoría en su visión general del proceso de presentación de informes financieros de la compañía, estas son requeridas por las normas de auditoría generalmente aceptadas. Entre las normas más importantes que regulan estos aspectos se tiene al SAS 90: "Comunicaciones con el comité de auditoría emitida por Instituto Americano de Contadores Públicos Certificados (AICPA) y el Consejo para la práctica 2060-2: «Relaciones con el comité 
de auditoría» emitido por The Institute of Internal Auditors (IIA)

No todas las empresas o entidades tienen comités de auditoría. Por ejemplo, el concepto de un comité de auditoría no se aplica a los negocios organizados como empresas de un solo propietario, sociedades y corporaciones pequeñas de propiedad limitada. Los convenios de auditoría de estas firmas se realizan con frecuencia con los propietarios, un socio o un ejecutivo, como el presidente, el tesorero o el contralor.

En el Perú, para el caso de las empresas bancarias, financieras, de seguros y de reaseguros, de conformidad a la Resolución SBS No 1040-99, del 26 de noviembre de 1999, que aprueba el reglamento del sistema de control interno, es obligatoria la constitución de un comité de auditoría. En el caso de aquellas empresas que expresamente no se encuentren obligadas a constituir comités de auditoría y que, además, decidan no constituirlos, todas las funciones atribuidas al comité de auditoría serán asumidas por el directorio.

\section{Importancia del Comité de Auditoría}

Reconocidas instituciones profesionales y gubernamentales sugieren en unos casos y obligan en otros, que las empresas y organizaciones cuenten con un comité de auditoría; entre estas instituciones, se puede mencionar a las siguientes:

- Comisión de Títulos, Valores y Cambios de EE.UU. (Securities and Exchange Commission, SEC).

- Instituto Americano de Contadores Públicos Certificados (AICPA).

- Instituto de Auditores Internos (IIA).

- Comité de Basilea.
- Comité COSO: Metodología de control interno.

- Comité COSO: Metodología de gestión de riesgos corporativo.

Y particularmente, en el Perú:

- Superintendencia de Banca y Seguros.

- Comisión Nacional Supervisora de Empresas y Valores (CONASEV).

- Fondo Nacional de Financiamiento de la Actividad Empresarial del Estado (FONAFE).

La importancia del comité de auditoría se puede resumir en los aspectos siguientes:

- Constituye un foro de análisis independiente, que le permite al consejo de directores (Directorio) conocer lo que sucede y reaccionar en consecuencia.

- Es una posibilidad de transformar un enfoque tradicional de auditoría a una actividad de consultoría de alto valor agregado, aprovechando la experiencia empresarial de los directores.

- Es un elemento clave para un eficiente y confiable mercado de capitales (atracción de inversionistas) y para lograr la confianza de acreedores y terceros.

- Es el motor principal de un programa de mejora continua, sin sustituir ni subsidiar a la administración.

\section{Principales funciones del Comité de Auditoría}

Las funciones del comité de auditoría que se consignan a continuación son las más conocidas y aceptadas; sin embargo, esta enunciación no debe considerarse como limitativa, sino únicamente como enunciativa:

- Responsable de la selección, designación, evaluación, compensación, 
supervisión y cese de auditores externos e internos.

- Confirmar el estatuto de auditoría interna y su plan de actividades, así como sus recursos.

- Asegurar la independencia de criterio de la actividad de auditoría externa e interna.

- Recibir informes resumidos de los trabajos de auditoría interna, sus recomendaciones y las medidas tomadas por la administración para ser implementadas.

- Adoptar procedimientos para el manejo de reportes relacionados con asuntos contables o de auditoría, incluyendo métodos anónimos y confidenciales para el manejo de reportes expresados por empleados.

- Reforzar los procesos de supervisión de la empresa.

- Entender y evaluar conjunto de riesgos, oportunidades y retos de su empresa.

- Evaluar la efectividad del control interno, el cumplimiento de disposiciones, los principios, criterios y prácticas contables correctas, las transacciones con terceros relacionados, la auditoría interna.

- Apoyar y proporcionar al consejo de administración (Directorio), mediante una opinión independiente y profesional, sobre el control interno y la auditoría externa e interna.

- Propiciar la comunicación entre los miembros del directorio, el gerente general, la auditoría interna y la auditoría externa.

- Informar al consejo de administración (Directorio) y a la junta general de accionistas.

- Debe entregar un reporte anual de sus actividades al consejo de administración (Directorio).

Debido a estos factores, como también a las reglas cada vez más complejas de con- tabilidad y control, el riesgo que corren los comités de auditoría, al llevar a cabo sus responsabilidades, es más grande que nunca.

\section{Principales responsabilidades del Comité de Auditoría}

La responsabilidad primaria del comité de auditoría es respecto de sus pares del directorio (consejo de administración), a quienes, además, debe asistir en el desarrollo de sus responsabilidades en cuatro áreas principales:

\section{Información financiera}

Asegurar que las revelaciones hechas por la administración razonablemente reflejan las condiciones financieras, los resultados de operación y los planes y compromisos a largo plazo; para lo cual, debe:

- Vigilar la función del auditor externo.

- Revisar las políticas de contabilidad.

- Examinar (confiabilidad y exactitud) los estados financieros periódicos y anuales.

\section{Gobierno corporativo}

Asegurar que la empresa u organización cumpla razonablemente con las leyes y regulaciones aplicables, se conduce éticamente en los negocios y mantiene un control efectivo contra posibles conflictos de intereses y fraudes; para lo cual principalmente se deberá:

- Revisar las políticas corporativas relacionadas al cumplimiento regulatorio.

- Revisar la situación de los litigios de la organización.

- Revisar los casos de fraude o conflicto de intereses de los empleados.

- Seguimiento al sistema de quejas y reportes de empleados, clientes y terceros.

- Requerir al auditor interno un reporte anual de puntos significativos. 
- Coordinar, apoyar y evaluar las actividades del área de auditoría interna.

\section{Control corporativo}

El entendimiento de los principales riesgos de la empresa u organización y el sistema de control interno implementado, auxiliándose del auditor interno para monitorear el proceso de control; para lo cual debe:

- Analizar la consistencia del modelo de negocio con respecto a las estrategias, objetivos y políticas de dirección planteadas por el consejo.

- Opinar y evaluar la suficiencia del sistema de control interno.

- Emitir los lineamientos de control interno (funcionamiento) y monitorear su cumplimiento.

- Asegurar la implantación y funcionamiento de un sistema de administración de riesgos.

\section{Cumplimento de normas y regulaciones} Cumplir con las normas y regulaciones que le son aplicables, con lo que además impartirá tono positivo desde lo alto; para lo cual debe:

- Cumplir las materias legales y regulatorias.

- Cumplir los acuerdos establecidos por el directorio.

\section{Características del los miembros del Comité de Auditoría}

La composición preferida del comité de auditoría es sin la inclusión de los directores (internos) y altos ejecutivos (empleados). Generalmente los comités de auditoría están compuestos de 3 a 5 directores externos, es decir, directores que no son empleados de ningún nivel de la empresa. La exclusión de los directores y altos empleados del comité de auditoría permite analizar más abiertamente diversos factores relacionados con la empresa.

Para la efectividad de los comités de auditoría, actualmente se exigen ciertas características que deben tener los comités, que les permitan cumplir con las responsabilidades que se les han definido. A continuación se mencionan diez características de un comité de auditoría efectivo:

1. El comité de auditoría debe regirse por los estatutos que le dan formalidad a su función, estos deben ser presentados al directorio (consejo de administración) para su aprobación. Los estatutos deberán definir claramente las responsabilidades y atributos del comité, así como la permanencia de sus miembros y los procedimientos para la reelección o nominación de candidatos y deberán estar sujetos a revisión cuando menos una vez por año.

2. Los comités deben contar con un número de miembros adecuado al tamaño de la organización para la que servirán y a las actividades que deberán de llevar a cabo como parte de sus funciones. Actualmente, las prácticas recomiendan un mínimo de tres miembros y un máximo de cinco.

3. Los comités de auditoría deben ser presididos e integrados por consejeros independientes a la organización. Este principio contribuye, de manera significativa, a asegurar la transparencia en la gestión del comité.

4. La experiencia de los miembros del comité debe ser cuidadosamente observa$\mathrm{da}$, de manera tal que en su conjunto reúnan las características necesarias para vigilar, evaluar y opinar sobre el cumplimiento de la estrategia del negocio; los procedimientos para la administración 
de riesgos de la organización; el sistema de control interno; la información financiera producida por la administración y los aspectos legales o de índole regulatorio. Asimismo, es recomendable que, cuando menos, uno de los miembros del comité cuente con una experiencia sólida en finanzas y contabilidad, de manera tal que le permita interpretar adecuadamente la información financiera y opinar sobre las políticas y criterios contables de la organización.

5. El comité de auditoría debe establecer y mantener líneas de comunicación abiertas con el directorio (consejo de administración), los auditores independientes, auditores internos y con la administración. Se deberán llevar a cabo reuniones periódicas con cada una de las áreas mencionadas, además de asegurar la adecuada coordinación entre el auditor interno y externo para una mayor eficiencia en su trabajo y contribución al negocio.

6. El comité de auditoría deberá contar con un programa de trabajo que le permita enfocarse hacia las situaciones relevantes en la organización. Se deberán definir agendas de trabajo, un calendario de reuniones formales anuales, siendo estas, cuando menos, cada tres meses. Asimismo, se recomienda que se cuente con sistemas de seguimiento a compromisos que permitan llevar una adecuada administración de cada tema y asignar prioridades y responsables.

7. El comité de auditoría requiere de un compromiso en cantidad y calidad de tiempo y debe ser proactivo.

8. El comité deberá contar con un presupuesto propio para su gestión y tener libre acceso a la contratación de asesores que le ayuden en el desarrollo de sus funciones.
9. Los miembros del comité deberán contar con un programa de actualización continua. Actualmente, en el mundo ya existen organizaciones dedicadas a la preparación y actualización de consejeros.

10. El comité de auditoría debe disponer de metodologías de autoevaluación que le permita conocer su grado de contribución y establecer los programas de mejora necesarios para elevar el desempeño del comité. Hoy en día existen herramientas como son los llamados self evaluation o self assesment que consideran algunos de los puntos a evaluar como capacidad de liderazgo, competencia, desempeño (indicadores), entre otros.

\section{Principios básicos para Comités de Auditoría}

- Reconocer que la dinámica de cada compañía, directorio, consejo y comité de auditoría es única, no hay un solo modelo para todos.

- El directorio deberá asegurarse de que el comité de auditoría integra a las "personas adecuadas» para poder tener una supervisión independiente y objetiva.

- El directorio y el comité de auditoría deberán continuamente asegurar y evaluar que el «mensaje de la alta dirección» incorpore e insista en la integridad y precisión en la generación de la información financiera.

- El comité de auditoría deberá exigir y continuamente reforzar y hacer saber al directorio, como representante que es de los accionistas, la trascendencia e importancia de la opinión y comentarios del auditor externo.

- Los comités de auditoría deben implantar un proceso que sustente su entendimiento y monitoreo. 
Deficiencias y debilidades más frecuentes del Comité de Auditoría

Estas son algunas preguntas que deberían hacerse los miembros de un comité de auditoría:

- ¿Tenemos un proceso que mida la calidad y no sólo la admisibilidad de las políticas contables, los procesos de reportes financieros y los controles internos?

- ¿Hemos logrado entender los procesos utilizados por la gerencia y los auditores externos e internos para identificar y monitorear los riesgos?

- ¿Cómo estamos valorando la efectividad de los auditores externos e internos?

- ¿Cómo hemos evaluado la independencia de los auditores externos e internos?

- ¿Hemos evaluado la calidad de las áreas financieras, contables y de auditoría interna?

- ¿Cómo mide el comité de auditoría nuestra propia efectividad?

Los comités de auditoría que ya operan en empresas latinoamericanas enfrentan debilidades en varios aspectos, tales como: planes de sucesión, falta de fuentes de análisis independientes para respaldar sus análisis $\mathrm{u}$ opiniones, adecuados canales para solucionar quejas y denuncias, así como falta de conocimiento sobre los riesgos que enfrentan sus empresas.

En este sentido, se hace necesario que los miembros del comité de auditoría cuenten con mayores y mejores programas de actualización, apoyo de metodología para analizar la información crítica de la organización, entender circunstancias, evaluar alternativas y presentar recomendaciones con una visión independiente; y finalmente, mayor tiempo dedicado al cumplimiento de su responsabilidad a efecto de tener una contribución profesional que realmente se traduzca en alto valor agregado para sus empresas.

\section{Evaluación y fortalecimiento del Comité de Auditoría}

Toda evaluación del desempeño y las consiguientes acciones de fortalecimiento del comité de auditoría, deberían considerar como mínimo los aspectos siguientes:

1. Composición y calidad.

2. Comprensión del negocio y de sus riesgos.

3. Procesos y procedimientos.

4. Comunicaciones e información.

5. Supervisión del proceso y controles internos para elaborar informes financieros, $y$

6. Supervisión de las funciones de auditoría.

\section{Beneficios de contar con un Comité de Auditoría}

Ya que hemos tratado las razones para contar con un comité de auditoría y las características de estos, es necesario definir los beneficios que una organización debe comprender y valorar al tener un órgano de gobierno independiente, cuyo objetivo es el contribuir de manera profesional y con un alto sentido de responsabilidad y ética al cumplimiento de objetivos estratégicos de la organización, y asegurar que las prácticas de negocio se den de acuerdo con las políticas establecidas por la junta de accionistas a través del directorio (consejo de administración).

Por citar algunos de los principales beneficios, sin tratar de ser exhaustivos, podemos mencionar los siguientes:

a) Se logra un mayor valor de la empresa al atraer inversionistas que buscan invertir 
en negocios que cuenten con estructuras y prácticas de buen gobierno corporativo dando, de esta manera, seguridad a su inversión.

b) Contribución al logro de objetivos estratégicos de la organización.

c) Mejora continua en las distintas áreas del negocio.

d) A nivel del directorio, se logra una adecuada comunicación y seguimiento sobre temas de relevancia que interesan a la organización al mantenerse debidamente informado a través del comité de auditoría.

\section{CONCLUSIONES}

En teoría, el rol de los comités de auditoría no ha cambiado, su responsabilidad permanece en vigilar la integridad y confiabilidad en los estados financieros de las empresas. Sin embargo, en la práctica, ser parte de un comité de auditoría se ha convertido en un trabajo más demandante y de mayor responsabilidad. Los reguladores han puesto más énfasis sobre la calidad del control interno en las empresas y compañías, y sobre las capacidades e independencia de los miembros del comité.

Muchas son las acciones realizadas por el regulador para incorporar cambios en las leyes y reglamentos relativos a comités de auditoría, haciendo que estos cumplan con las necesidades del mundo actual de negocios. Sin embargo, las organizaciones no debieran implementar prácticas de buen gobierno, únicamente por dar cumplimiento a la regulación, se deben valorar los beneficios de contar con estas y provocar un cambio cultural en sus organizaciones, de manera que se disfruten los beneficios de contar con estructuras y buenas prácticas de gobierno corporativo.
En el proceso de gobierno corporativo, el comité de auditoría desarrolla un rol clave, ya que otorga mayor valor a la empresa (incrementa los resultados y el valor de la acción) y facilita la atracción de capitales, dando confianza a acreedores e inversionistas. Asimismo, propicia y contribuye con el cumplimiento de normas y regulaciones, $y$ otorga mayor seguridad a los miembros del directorio, en cuanto a sus funciones y responsabilidades.

El comité de auditoría permite la adopción de un plan de control y gobierno corporativo con impacto real en los objetivos del negocio que generan mejoras específicas $y$ permanentes en las distintas áreas y procesos de negocios.

La efectividad y transparencia de un comité de auditoría requiere principalmente que sus miembros sean independientes de la empresa u organización en donde prestan servicios, que tengan amplia experiencia en el área financiera, de auditoría y de control (por lo menos uno de ellos debe ser un experto financiero), que puedan conocer y supervisar los procesos de gestión de los negocios, gestión de riesgos y el sistema de control interno de la empresa, y que solo puedan ser removidos previa resolución tomada por el directorio (consejo de administración).

\section{RECOMENDACIONES}

Las organizaciones deben implementar prácticas de buen gobierno, como el establecimiento de un comité de auditoría, no solamente por cumplir con las leyes y reglamentos, sino por obtener los beneficios que otorga este comité, pues ello conlleva a un sano cambio cultural en la organización y contar con las buenas prácticas de un gobierno corporativo. 
El comité de auditoría debe contar con reglamentos que le den formalidad a su función, estos deben de ser presentados al directorio (consejo de administración) para su aprobación. Los reglamentos deberán definir claramente las responsabilidades y atributos del comité, así como la permanencia de sus miembros y los procedimientos para reelección o nominación de candidatos y deberán ser revisados periódicamente.

El comité de auditoría debe establecer y mantener líneas de comunicación abiertas con el consejo de administración, los auditores externos, auditores internos y con la administración. Se deben llevar a cabo reuniones periódicas con cada una de las áreas mencionadas, además de asegurar la adecuada coordinación entre el auditor interno y externo para una mayor eficiencia en su trabajo y contribución al negocio.

\section{REFERENCIAS}

Bell, Timothy. Auditoría basada en riesgos. Bogotá, Colombia, ECOE Ediciones, 2007, 263 pp.

Blanco Luna, Yanel. Normas y procedimientos de la auditoría integral. Colombia, ECOE Ediciones, 2003, 324 pp.
Committee Of Sponsonsoring Organizations (COSO), Of the Treadway Commission. Control interno. EE.UU., Ediciones ECOE, 1996, $321 \mathrm{pp}$.

Consejo para la práctica 2060-2: «Relaciones con el comité de auditoría» emitido por The Institute of Internal Auditors (IIA).

Ley Sarbanes-Oxley (U.S. Congress Sarbanes-Oxley Act of 2002), SAS 90: «Comunicaciones con el comité de auditoria» emitida por Instituto Americano de Contadores Públicos Certificados (AICPA).

Mantilla Blanco, Samuel. Auditoría 2005. Bogotá, Colombia, ECOE Ediciones, 2003, 1067 pp.

Mantilla Blanco, Samuel y Sandra Yolita Cante. Auditoría del control interno. Bogotá, Colombia, ECOE Ediciones, 2005, 283 pp.

Resolución SBS No 1040-99 del 26 de noviembre de 1999 que aprueba el reglamento del sistema de control interno. 